\title{
Populismo y desafíos de la representación política en las democracias contemporáneas
}

\author{
[Populism and challenges of political \\ representation in contemporary democracies] \\ Claudia Heiss (1) \\ Universidad de Chile
}

\section{Resumen}

El artículo ofrece un análisis crítico del concepto de representación política y su relación con el fenómeno del populismo. Se argumenta que la desafección con la representación obedece a la incapacidad de las democracias representativas de cumplir su promesa de inclusión y progresiva democratización social por medio de las instituciones. Se discute la promesa incumplida de la democracia representativa de materializar los ideales democráticos de autogobierno y soberanía popular. Luego, se describen distintas formas de entender el fenómeno del populismo. Por último, se concluye que la crisis de la representación política tiene una directa relación con el surgimiento de gobiernos populistas, producto de la incapacidad del sistema de democracia representativa de dar cabida a su promesa de inclusión, subordinando clivajes políticos tradicionales como la división izquierda-derecha a la dicotomía pueblo-élite.

Palabras clave: representación, populismo, democracia, participación, inclusión.

\begin{abstract}
The article presents a critical analysis of the concept of political representation and its relationship with the phenomenon of populism. Disaffection with representation, it is argued, results from the inability of representative democracies to fulfill their pledge of inclusion and increasing social democratization through institutional means. The broken promise of representative democracy to achieve the democratic ideals of self-government and popular sovereignty is addressed. Lastly, it is argued that the crisis of political representation is directly related to the rise of populist governments, which, due to the inability of systems of representative democracy to deliver on their promise of inclusion, end up subordinating traditional political cleavages such as the left-right divide to the dichotomy of "the people" versus "the elite".
\end{abstract}

Keywords: representation, populism, democracy, participation, inclusion. 


\section{INTRODUCCIÓN}

La desconfianza en las instituciones de la representación política ha significado para las principales democracias representativas del mundo una tendencia a la reducción tanto de la participación electoral como de la adhesión a partidos políticos y apoyo a las instituciones representativas. Esta desafección hacia las formas institucionalizadas de canalización de preferencias, ideas, valores y demandas desde la sociedad a la esfera de la decisión política parece hoy poner en tela de juicio incluso a democracias representativas consolidadas que se consideraban inmunes a cuestionamientos a la legitimidad de su orden institucional.

Huntington (1991) identificó las transiciones a la democracia ocurridas entre 1974 y 1990 en más de treinta países como una "tercera ola" de democratización. En su análisis, a cada ola democratizadora le sigue una "contraola" en un movimiento pendular según el cual periodos históricos de expansión democrática son sucedidos por periodos de contracción en los que priman las transiciones desde la democracia al autoritarismo. Siguiendo ese razonamiento, Levitsky y Ziblatt (2018) han advertido que las democracias actuales están en peligro. Pero a diferencia de la segunda contraola, señalan, hoy las democracias no mueren producto de golpes de Estado o revoluciones, sino a partir de la corrosión interna de los sistemas democráticos por parte de líderes populistas que utilizan las herramientas de la propia democracia representativa para destruirla, concentrando el poder, horadando los contrapesos institucionales en nombre del apoyo electoral y derivando en la cooptación del sistema político y el fin del pluralismo. La muerte de la democracia aparece así asociada tanto a la decadente legitimidad de la representación política como al surgimiento de populismos.

Este diagnóstico ha generado dos bandos (Ruth, Welp \& Whitehead, 2017; Urbinati \& Warren, 2008). Por un lado, la visión elitista culpa a líderes populistas hambrientos de poder y a una ciudadanía carente de educación cívica por no cuidar las instituciones de la democracia representativa, posición que con frecuencia descalifica las críticas a la representación política. Por otro lado, la visión centrada en la promesa de soberanía popular culpa a la naturaleza excluyente y oligárquica de la representación por la incapacidad de los sistemas políticos de hacer realidad el ideal democrático de autogobierno, proponiendo modelos alternativos de democracia participativa que permitan superar el principio excluyente de la representación. Esta posición, sin embargo, no logra dar respuesta a la incapacidad de la participación no representativa de generar espacios de deliberación ni de corregir asimetrías de voz y poder en la toma de decisiones.

Este artículo ofrece un análisis crítico del concepto de representación política, así como de su relación con el fenómeno del populismo, a fin de contribuir a una comprensión de estos fenómenos considerando las dos posiciones antes descritas. Se argumenta que la desafección con 
Heiss, C. (2020). Populismo y desafíos de la representación política en las democracias contemporáneas. Revista de Sociología, 35(2), 30-41. doi: 10.5354/0719-529X.2020.58646

la representación obedece a la incapacidad de las democracias representativas de cumplir su promesa de inclusión y democratización social. Tomar en serio este reclamo es el punto de partida para habilitar una democracia efectiva en sus dimensiones de participación, deliberación y representación política.

\section{LA PROMESA INCUMPLIDA DE LA DEMOCRACIA REPRESENTATIVA}

Pitkin (1967| 2014) inauguró una nueva vertiente en el análisis de la representación política, ahondando en la complejidad de ese concepto, hasta entonces poco discutido. A casi 20 años de la publicación original, Pitkin (1967| 2014) escribió un prefacio para la edición española donde se lamenta de las omisiones de su obra: "lo que ocurre es que este libro simplemente no considera con seriedad la cuestión de que las instituciones representativas puedan traicionar en vez de servir a la democracia y la libertad" (Pitkin 1967|2014, p. 11). En años posteriores, el estudio de la representación pasó de ser un tema virtualmente ignorado a ocupar el centro de las preocupaciones teóricas y políticas.

A pesar de no hacerse cargo de la relación problemática entre democracia y representación, el trabajo de Pitkin (1967|2014) fue pionero en divorciar el concepto de representación de la idea de democracia: "un rey puede representar a una Nación, y también puede hacerlo un embajador. Cualquier servidor público puede representar en algunas ocasiones al Estado (...) sin que ello tenga nada que ver con el autogobierno del pueblo" (Pitkin, 1967|2014, p. 14). De este modo, Pitkin abrió el camino a futuros estudios críticos de la representación política. Su análisis sitúa el origen de la representación en la modernidad. A partir de los siglos XIII y XIV, personas enviadas a participar en concilios eclesiásticos o en el parlamento inglés son descritas como representantes, es decir, como seres humanos que actúan por otros. Esas funciones de representación no se relacionan con elecciones ni con el principio democrático. De hecho, el concepto moderno de representación nace con la persona pública de Hobbes (1651 | 1985), que representa a todos los individuos del pacto social. Sin embargo, la revolución de Estados Unidos contra la corona británica tuvo como lema "impuestos sin representación es tiranía", y la revolución francesa estableció la representación como uno de los derechos del hombre. De este modo, la "representación vino a significar representación popular, guardando una estrecha relación con la idea de autogobierno, con el derecho que cada hombre tiene a decir lo que piensa. Y así es como llegó a encarnarse en nuestras instituciones." (Pitkin, 1967|2014, p. 16).

Pitkin (1967|2014) distingue cuatro sentidos distintos que se dan el término representación: (a) el formal, con sus dimensiones de autorización y accountability (rendición de cuentas); (b) el simbólico, (c) el descriptivo, y (d) el sustantivo. La representación formal se refiere a los arreglos institucionales que preceden e inician la representación. La autorización de la representación formal es el 
Heiss, C. (2020). Populismo y desafíos de la representación política en las democracias contemporáneas. Revista de Sociología, 35(2), 30-41. doi: 10.5354/0719-529X.2020.58646

mecanismo que permite al representante ejercer ese papel. Hoy el principal mecanismo es la autorización electoral. La rendición de cuentas se refiere a la capacidad del representante de responder a sus electores o recibir su castigo en las urnas si no lo hace. La representación simbólica alude al significado que tiene para quienes son representados la presencia del representante. Esto tiene que ver con el grado de aceptación que despierta en los representados. La representación descriptiva es el grado en que los representantes se parecen a sus representados. Esta categoría fue considerada en forma crítica por Pitkin (1967|2014), ya que dificulta la rendición de cuentas. Sin embargo, con el tiempo y el desarrollo de la política del reconocimiento a partir de la década de 1970, adquirió creciente relevancia y fue clave para la distinción que realizaría Phillips (1995) entre política de la presencia (descriptiva) y de las ideas (sustantiva). Sólo que esta vez, la presencia pasaría a ser un componente necesario para la legitimidad de sistemas políticos capaces, gracias a ella, de dar una señal de no-exclusión de grupos en consideración de características étnicas, culturales o de género. Por último, la representación sustantiva se refiere a las acciones ejercidas en nombre, en interés, como agente, o como sustituto de los representados. Esta dimensión, equivalente a la política de las ideas de Phillips (1995), alude a la representación ideológica, de intereses, valores y preferencias.

La tensión entre representación y democracia es visible en las primeras conceptualizaciones sobre el gobierno representativo, que se presenta como una alternativa al gobierno de la mayoría. Tanto
Locke (1690| 1980), como Madison (ver: Hamilton, Jay \& Madison, 1788) apuntan a desplazar al representado y a buscar una versión depurada de sus intereses a través del representante. Rousseau (1762) critica esa idea señalando que la soberanía no puede ser representada y proponiendo que sólo el gobierno de asamblea, es decir, la democracia directa, puede develar la voluntad general, que es sinónimo del bien común.

Autores contemporáneos críticos de la representación, como Pateman (1976) y Barber (1984), han sostenido visiones herederas de Rousseau (1762), señalando que la representación sólo se justifica como un sustituto deficiente de la democracia directa cuando ella es imposible por razones prácticas. Desde la década de 1960, quienes buscaban expresiones de democracia más robustas que la competencia electoral comenzaron a elaborar modelos de democracia participativa y deliberativa desvinculados de la representación política. Al mismo tiempo, la representación quedó reducida a una definición neo-Schumpeteriana de democracia como un asunto de selección y organización de las élites políticas (Schumpeter, 1976; Urbinati \& Warren, 2008). Esa suerte de división del trabajo en el mundo académico comenzó, sin embargo, a verse desafiada con la problematización de la política de la presencia y la comprensión de la exclusión política como una falla principalmente en la capacidad de las instituciones de representar el pluralismo social (Urbinati \& Warren, 2008).

El influyente trabajo de Manin (1998) contribuyó, sin quererlo, a la visión de la representación como antidemocrática. En su libro argumenta que la elección es por definición un mecanismo oligárquico, mientras que el mecanismo verdaderamente 
Heiss, C. (2020). Populismo y desafíos de la representación política en las democracias contemporáneas. Revista de Sociología, 35(2), 30-41. doi: 10.5354/0719-529X.2020.58646

democrático es el sorteo, tal como se usaba en la antigua Atenas para seleccionar algunos cargos públicos. La elección es inherentemente excluyente de un pueblo que, tras votar, se torna pasivo hasta la siguiente elección (Manin, 1998). Este enfoque pone el énfasis en formas activas y pasivas de inclusión, y no en aquellos sectores excluidos de la representación, como hacen Phillips (1995) en torno a la exclusión de género y Kymlicka (1996) en torno a la exclusión étnica y cultural. Es precisamente el foco en estos grupos marginados de la representación lo que generó el interés de la teoría democrática en el problema de la representación ya no desde un enfoque minimalista y electoral sino robusto (Urbinati \& Warren, 2008).

En lugar de abandonar la representación a las teorías elitistas, autores como Plotke (1997), Urbinati (2006) y Peruzzotti (2008), se propusieron darle un nuevo sentido, relacionado con la participación y la deliberación política. Dada la complejidad de la representación y sus múltiples dimensiones, no existe persona capaz de representar por completo a otra en la esfera pública. Entendida así, la representación debe ser permanentemente recreada en un vínculo sostenido entre representantes y representados, y no sólo actualizada en periodos electorales. Los representantes no reemplazan a sus representados al ser electos. La identificación política nunca es completa, y en consecuencia los representados permanecen como una ciudadanía activa en el curso del proceso de representación. Los trabajos que buscan resignificar la representación política alejándola de la concepción elitista no ven en la participación y la deliberación elementos contrarios a una representación que desplazaría al pueblo. Por el contrario, buscan dar a la representación el sentido de una "política mediada", donde participación y representación se complementan. En otras palabras, proponen establecer una suerte de puente entre estos dos campos (Peruzzotti, 2008). Reivindicando la representación para el ámbito democrático, Plotke (1997) señala que lo opuesto de la representación no es la participación sino la exclusión. Y que lo opuesto de la participación es la abstención. La representación, en este sentido, no es un mal menor frente a la imposibilidad práctica de la democracia directa, sino un elemento crucial para constituir prácticas democráticas.

Los intentos por resignificar la representación política apuntan a su potencial para la inclusión equitativa en la toma de decisiones y a su capacidad única de generar espacios de deliberación. Sin embargo, el esfuerzo por construir una noción democrática de representación debe partir por reconocer las limitaciones que han tenido en la práctica las democracias representativas.

Las teorías de la democracia deliberativa (e.g., Elster, 2000; Fishkin, 1995; Habermas, 2010) señalan que la representación es una condición necesaria para la existencia de cuerpos deliberativos. Sin embargo, esta representación no es solo de carácter electoral. No sólo en parlamentos y órganos colegiados autorizados por elecciones se generan espacios de deliberación, sino también en espacios donde distintos actores reclaman representatividad, tanto desde la política institucional como desde la no institucional. En la era de la desconfianza, la "contrademocracia" (Rosanvallon, 2007) permite el control del poder por vías distintas de la representación electoral. Es "la 
Heiss, C. (2020). Populismo y desafíos de la representación política en las democracias contemporáneas. Revista de Sociología, 35(2), 30-41. doi: 10.5354/0719-529X.2020.58646

democracia de los poderes indirectos diseminados en el cuerpo social, la democracia de la desconfianza organizada frente a la democracia de la legitimidad electoral" (Rosanvallon 2007, p. 27).

Las formas no electorales de participación, como la movilización social o el activismo en organizaciones no gubernamentales y otras instituciones, no pierden su carácter de participación política por el hecho de estar fuera de los canales institucionalizados de la política. Del mismo modo, surgen nuevas formas de representación que disputan la hegemonía que hasta hace algunas décadas tuvieron los partidos políticos. Si las personas no votan, pero participan a través de otros métodos, la teoría debe adaptarse a la realidad y no considerar ese comportamiento como despolitización o ausencia de participación. Hoy parecen necesarios nuevos marcos conceptuales para entender la representación política más allá de las instituciones. La promesa incumplida de la democracia representativa ha generado disputas de representación, como las que vemos cuando un grupo de ciudadanos se considera mejor representado por una multitud en la calle que por sus representantes electos sobre una base de pertenencia territorial.

Urbinati y Warren (2008) distinguen nuevas formas de representación por parte de colectivos auto-autorizados para representar a una comunidad o por parte de una ciudadanía representante. Estas formas se superponen con la representación electoral, con sus ciclos de autorización y rendición de cuentas a través de la reelección. El hecho de ir a la reelección previene abusos gruesos de poder. Sin embargo, la simple reelección o no reelección carece de suficientes matices y sensibilidad para cubrir las necesidades continuas de la representación política. Es por eso que la representación electoral funciona a veces en competencia y a veces en combinación con una serie de otras formas de representación más sensibles a los cambios y demandas de la ciudadanía. (Urbinati \& Warren 2008).

\section{CONCEPTUALIZACIONES DEL POPULISMO}

El concepto de populismo (que deriva de la expresión latina populus) es un fenómeno asociado a la democracia (que deriva su nombre del griego demos). Ambos conceptos apelan a un principio mayoritario. No tendría sentido hablar de populismo en un sistema donde la autoridad política tiene legitimidad divina. Por el contrario, sólo allí donde la noción democrática de soberanía popular es la que justifica al poder político se vuelve relevante la apelación a la masa o la mayoría. Con todo, se suele concebir al populismo como un enemigo de la democracia (e.g., Levitsky \& Ziblatt, 2018; Weyland, 2001).
El concepto de populismo es difícil de asir. No sólo existe un intenso debate sobre qué es y qué no es populismo, sino también sobre cuál es la mejor estrategia para definirlo (para mayores antecedentes sobre el debate actual, consulte: Casullo, 2019; Judis, 2016; Mudde \& Rovira, 2019; Panizza, 2009; Rivero, Zarzalejos \& Del Palacio, 2017). Eso dependerá, en parte, de para qué fines se construya la definición (e.g., para la comparación empírica, el análisis histórico o la elaboración conceptual). Casullo (2015) destaca que mientras para algunos el populismo "estará 
Heiss, C. (2020). Populismo y desafíos de la representación política en las democracias contemporáneas. Revista de Sociología, 35(2), 30-41. doi: 10.5354/0719-529X.2020.58646

siempre reñido con la democracia”, para otros "es una parte constitutiva" de ella (p. 278).

Desde una definición económica, se suele calificar de populista una "mala administración" caracterizada por la redistribución excesiva de recursos a sectores populares para lograr éxitos electorales inmediatos, a sabiendas de que esta política no es sustentable en el mediano plazo (Casullo, 2015; Mudde \& Rovira, 2019). Sin embargo, la existencia de gobiernos populistas neoliberales en América Latina desafía esta definición. En este sentido, parece incorrecto definir el populismo como equivalente a determinadas políticas económicas.

Entre las definiciones propiamente políticas de populismo, Casullo (2015) identifica tres tradiciones. La primera, de raigambre sociológica, se centra en las coaliciones de clase de finales de las dos guerras mundiales, asociando el populismo con los fenómenos de modernización e industrialización. La segunda surge a partir de los populismos neoliberales de las décadas de 1980 y 1990. Esta definición es más propiamente politológica, al entender el populismo como una manera específica de competir por y de ejercer el poder. Una tercera versión ve en el populismo una práctica política democrática, donde democracia liberal y populista no son tipos de régimen dicotómicamente diferentes, sino tipos relacionales, siempre en tensión y competencia. Esta es la versión de autores como Laclau (2005) y Mouffe (2018). Para Laclau (2005), el populismo es un discurso político performativo que tiene como objetivo la formación de identidades políticas mediante la dicotomización discursiva del campo político entre un nosotros y un ellos. El énfasis de esta noción de populismo está en la dimensión político-discursiva, más que en las sociológica y económica, y es tal vez la única que reivindica al populismo como una estrategia positiva para una política democrática.

Mudde y Rovira (2019), desde un enfoque ideacional afirman que el populismo es

una ideología delgada, que considera a la sociedad dividida básicamente en dos campos homogéneos y antagónicos: el 'pueblo puro' frente a la 'elite corrupta', y que sostiene que la política debe ser la expresión de la voluntad general del pueblo (p. 33).

El pueblo y la elite no son entidades esenciales sino comunidades imaginadas que se construyen de manera muy diferente según de qué experiencia populista se trate (Casullo, 2015). Ostiguy (1997) define al populismo en términos culturales como aquellas formas que apelan a lo bajo en política, es decir, que involucran la utilización política de modos de sociabilidad y modos estéticos de las clases populares. Así, para Ostiguy (1997) lo relevante no es observar ciertas políticas públicas particulares ni tampoco las alianzas de clase, sino la activación política de aquellas marcas que segregan culturalmente a las clases populares. Por su parte, Murillo (2018) objeta la falta de historicidad de las definiciones de populismo como discurso o ideología. En el caso latinoamericano, señala que es esencial indagar en la construcción del concepto de soberanía popular, la histórica debilidad de los Estados y el impacto de los ciclos político-económicos para entender las diversas formas de populismo que han surgido en la región. Arato (2019) considera que el populismo no es propiamente una ideología, sino "una identidad política” con cuatro características. Primero, se 
Heiss, C. (2020). Populismo y desafíos de la representación política en las democracias contemporáneas. Revista de Sociología, 35(2), 30-41. doi: 10.5354/0719-529X.2020.58646

legitima en términos de soberanía popular refiriéndose a una parte de la población como si fuera el todo, es decir, el pueblo (i.e., el demos, la comunidad política) o la Nación (i.e., el ethnos en la versión nativista). Se trata de un "mayoritarismo" que dice encarnar al pueblo, pero desconoce que puede ser en realidad una minoría que genera una mayoría ficticia producto de reglas electorales o de la abstención electoral. Segundo, construye cadenas de equivalencia retóricas (es decir, demandas específicas que, en un contexto de conflicto, adquieren universalidad y son retomadas por otras demandas específicas en una suerte de concatenación) a partir de demandas heterogéneas e incompatibles entre sí. Tercero, establece relaciones amigo-enemigo con una frontera de antagonismo radical. Por último, identifica la voluntad popular con la voluntad de un grupo. Para mantener la unidad, esa voluntad se encarna en un líder, generalmente el jefe del poder ejecutivo. Arato (2019) señala que estas características deben ser suplementadas con consideraciones históricas y contextuales.

El populismo involucra, en general, una identidad tenue que suele requerir el apoyo de otra ideología.
Por ejemplo, el nacionalismo, el socialismo, o alguna religión (Arato, 2019; Judis, 2019). Es por eso que, según la ideología en que se apoya, hay populismos de izquierda o derecha. Esto determinará cuál es la parte que se identifica con el todo y a quiénes se define como enemigos. Para los populismos de izquierda, el enemigo son las élites y actores externos. Para los de derecha también el enemigo son las élites, en especial la intelligentsia progresista y cosmopolita, pero además los populismos de derecha se caracterizan por tener alguna minoría como enemigo específico: inmigrantes, grupos religiosos o culturales, etc. (Judis, 2019). Tanto Urbinati (2015) como Arato (2019) enfatizan que los gobiernos populistas tienden a concentrar poder en el ejecutivo, a expensas del poder legislativo y el judicial. Arato (2019) señala que una vez que llegan al poder, los gobiernos populistas atacan la independencia de los máximos tribunales: Corte Suprema y Tribunal Constitucional. Esto equivale, para Arato (2019), a un ataque al constitucionalismo, encarnado en la supresión de la autonomía judicial.

\section{EL POPULISMO COMO FRACASO DE LA REPRESENTACIÓN}

Rechazar el potencial autoritario del populismo no significa desconocer que este fenómeno puede ser y ha sido en la historia de América Latina una fuerza integradora de sectores sociales excluidos y un impulso a modificar el statu quo oligárquico. ¿Será posible concebir esfuerzos redistributivos y populares sin el componente de rechazo a la representación política implícito en los proyectos populistas? En otras palabras, ¿es concebible en la región una política inclusiva no populista? En esa dirección apunta De la Torre (2017) cuando sostiene que "en lugar de tratar de forjar un pueblo unitario hay que partir de la diversidad de propuestas de los movimientos sociales y de organizaciones políticas para democratizar la política, la economía y las prácticas culturales" (p. 67). La representación entiende al pueblo no 
Heiss, C. (2020). Populismo y desafíos de la representación política en las democracias contemporáneas. Revista de Sociología, 35(2), 30-41. doi: 10.5354/0719-529X.2020.58646

como una unidad homogénea, sino como un ente plural y en permanente reconstrucción, es decir, como una "comunidad imaginada" (Anderson, 1993). Las intensas formas de identificación con un pueblo unitario propias del populismo se oponen a la representación de tipo electoral, pero también a otras concepciones más robustas de representación. El populismo construye al pueblo como una unidad en oposición a las elites (Casullo, 2019; Judis, 2016; Mudde \& Rovira, 2019). Si los gobiernos populistas constituyen una amenaza autoritaria para la democracia representativa, es posible que una concepción puramente electoral de la representación sea más parte del problema que de la solución. Eludir el populismo requeriría una democracia representativa capaz de incorporar la diversidad social y traducirla de manera efectiva en decisión política. Parte importante de la teoría democrática contemporánea se ha volcado al proyecto de resignificar la representación, a fin de desanclar este concepto de la visión minimalista e involucrar, en cambio, dimensiones tanto institucionales como extrainstitucionales de participación. En esta línea se inscriben autores como Plotke (1997), Urbinati (2006) y Peruzzotti (2008).

La desconfianza en instituciones que, bajo la consigna de representar, excluyen y concentran el poder, ha llevado a establecer mecanismos de control y obstrucción propios de la contrademocracia (Rosanvallon, 2007). Al mismo tiempo, la desconfianza ha contribuido a generar una democracia "impolítica", donde el ciudadano elector es reemplazado por el ciudadano controlador, con poder de obstrucción más que de agencia: "El ciudadano se ha transformado en un consumidor político cada vez más exigente, renunciando tácitamente a ser productor asociado del mundo común" (Rosanvallon 2007, p. 247). Paradójicamente, mientras las democracias de la tercera ola todavía abarcan más países que nunca antes en la historia, una concepción estrecha de la representación mantiene en muchos países una preocupante oligarquización de las decisiones políticas. Aunque formalmente persiste la democracia, el poder político se ha transferido desde un electorado mediado por partidos a pequeñas elites económicas y políticas. Las instituciones formales de la democracia no reflejan que el poder político sustantivo se encuentra concentrado y monopolizado por esas elites. El verdadero peligro para la democracia representativa se encuentra, entonces, en la oligarquización de la política, la que puede terminar imponiendo la dicotomía pueblo-élite a expensas del pluralismo y finalmente de la democracia misma

\section{CONCLUSIONES}

La tercera contraola de las democracias ha traído consigo liderazgos populistas que reclaman una representación total y totalizante de la ciudadanía, minando los frenos al poder en nombre de una identidad no mediada entre gobernantes y gobernados.
Ejemplos de este fenómeno se han observado recientemente en Perú, Rusia, Venezuela, Israel, Hungría, Turquía y Polonia. En todos ellos, los gobernantes muestran tendencias autoritarias a concentrar el poder y atacar la independencia 
Heiss, C. (2020). Populismo y desafíos de la representación política en las democracias contemporáneas. Revista de Sociología, 35(2), 30-41. doi: 10.5354/0719-529X.2020.58646

legislativa y judicial (Arato, 2019; Levitsky \& Ziblatt, 2018). Este trabajo ha intentado evidenciar un nexo entre dicho fenómeno y la crisis de legitimidad de la representación política. El descrédito en la representación se debe, en esta lectura, a su incapacidad de cumplir la promesa democrática de inclusión y autogobierno.

Frente a la crisis de una representación política entendida principalmente como autorización electoral del ejercicio del poder, algunos autores (Barber, 1984; Pateman, 1976) han propuesto reemplazar la democracia representativa por mecanismos de autogobierno más robustos, centrados en la participación y en la deliberación. Otros (Peruzzotti, 2008; Plotke, 1997; Urbinati, 2006) han sostenido que la representación es requisito para la existencia de grupos deliberativos y para contrarrestar la desigualdad de poder y de voz que caracteriza a la participación no representativa.

El discurso "nosotros" versus "ellos" propio del populismo (Arato, 2019; Casullo 2019; De la Torre, 2017; Judis, 2016; Laclau, 2005; Mouffe, 2018; Mudde \& Rovira, 2019; Urbinati, 2015) se construye a partir de un modelo de toma de decisiones percibido como elitista y excluyente, y no como expresión de una comunidad de fines e intereses entre gobernantes y gobernados. Vincular la literatura sobre crisis de la representación con trabajos recientes sobre populismo puede contribuir a una mejor comprensión del nexo entre ambos fenómenos. De esta manera, se evitará confundir el síntoma del populismo con la verdadera enfermedad: la promesa incumplida de una representación política democrática.

\section{REFERENCIAS}

Anderson, B. (1993). Comunidades imaginadas. Reflexiones sobre el origen y la difusión del nacionalismo. México D.F.: Fondo de Cultura Económica.

Arato, A. (2019). Populism, constitutional courts, and civil society. En C. Landfried (Ed.), Judicial power. How constitutional courts affect political transformations (pp. 318-341). Cambridge, Reino Unido: Cambridge University Press.

Barber B. (1984). Strong democracy. Los Angeles, CA: University of California Press.

Casullo, M. (2015). ¿En el nombre del pueblo? Por qué estudiar al populismo hoy. POSTData, 19(2), 277-313. Recuperado de http://www.revistapostdata.com.ar/
Casullo, M. (2019). ¿Por qué funciona el populismo? El discurso que sabe construir explicaciones convincentes en un mundo en crisis. Buenos Aires, Argentina: Siglo XXI Editores.

De la Torre, C. (2017). El populismo y la promesa de una democracia más inclusiva. En A. Rivero, J. Zarzalejos \& J. Del Palacio (Coords.), Geografía del populismo. Un viaje por el universo del populismo desde sus orígenes hasta Trump (pp. 54-68). Madrid, España: Editorial Tecnos.

Elster, J. (Comp). (2000). La democracia deliberativa. Barcelona, España: Editorial Gedisa.

Fishkin, J. (1995). Democracia y deliberación: Nuevas perspectivas para la reforma democrática. Barcelona, España: Editorial Ariel. 
Heiss, C. (2020). Populismo y desafíos de la representación política en las democracias contemporáneas. Revista de Sociología, 35(2), 30-41. doi: 10.5354/0719-529X.2020.58646

Habermas J. (2010). Facticidad y validez: Sobre el derecho y el Estado democrático de derecho en términos de teoría del discurso. Madrid, España: Editorial Trotta.

Hamilton, A., Jay, J., \& Madison, J. (1788). The federalist: A collection of essays, written in favour of the new constitution, as agreed upon by the federal convention, September 17, 1787. New York, NY: J. and A. McLean.

Hobbes, T. (1651|1985). Leviathan. Edited with an introduction by C.B. Macpherson. Londres, Reino Unido: Penguin Random House Grupo Editorial.

Huntington, S. (1994). La tercera ola: La democratización a finales del siglo $X X$. Buenos Aires, Argentina: Ediciones Paidós.

Judis, J. (2016). The populist explosion: How the great recession transformed American and European politics. New York, NY: Columbia Global Reports. Kymlicka W. (1996). Ciudadanía multicultural: Una teoría liberal de los derechos de las minorías. Barcelona, España: Ediciones Paidós.

Laclau, E. (2005). La razón populista. Buenos Aires, Argentina: Fondo de Cultura Económica.

Levitsky, S., \& Ziblatt, D. (2018). Cómo mueren las democracias. Barcelona, España: Editorial Ariel.

Locke, J. (1690 | 1980). Second treatise of government. Indianapolis, IN: Hackett.

Manin, B. (1998). Los principios del gobierno representativo. Madrid, España: Alianza Editorial.

Mouffe, C. (2018). Por un populismo de izquierda. Buenos Aires, Argentina: Siglo XXI Editores.

Mudde, C., \& Rovira C. (2019). Populismo. Una breve introducción. Madrid, España: Alianza Editorial.
Murillo, V. (2018). La historicidad del pueblo y los límites del populismo. Nueva Sociedad, 274, 165175. Recuperado de http://nuso.org/

Ostiguy, P. (1997). Peronism and anti-peronism: Social-cultural bases of political identity in Argentina. Trabajo presentado en laXXInternational Congress of the Latin American Studies Association (LASA), Guadalajara, México, 17 al 19 de abril. Recuperado de http://biblioteca.clacso.edu. ar/ar/libros/lasa97/ostiguy4.pdf

Panizza, F. (Comp). (2009). El populismo como espejo de la democracia. Buenos Aires, Argentina: Fondo de Cultura Económica.

Pateman C. (1976). Participation and democratic theory. Cambridge, Reino Unido: Cambridge University Press.

Peruzzotti, E. (2008). La democracia representativa como política mediada: Repensando los vínculos entre representación y participación. Debates en Sociología, (33), 9-30. Recuperado de http://revistas.pucp.edu.pe/index.php/debatese nsociologia/

Phillips, A. (1995). The politics of presence. Oxford, Reino Unido: Clarendon Press.

Pitkin, H. (2014). El concepto de representación. Madrid, España: Centro de Estudios Políticos y Constitucionales.

Plotke, D. (1997). Representation is democracy. Constellations, 4(1), 19-34. doi:

10.1111/1467-8675.00033

Rosanvallon, P. (2007). La contrademocracia. La política en la era de la desconfianza. Buenos Aires, Argentina: Ediciones Manantial. 
Heiss, C. (2020). Populismo y desafíos de la representación política en las democracias contemporáneas. Revista de Sociología, 35(2), 30-41. doi: 10.5354/0719-529X.2020.58646

Rivero, A., Zarzalejos, J., \& Del Palacio, J. (Coords). (2017). Geografía del populismo. Un viaje por el universo del populismo desde sus orígenes hasta Trump. Madrid, España: Editorial Tecnos.

Rousseau, J.-J. (1762). Du contrat social; Ou, principes du droit politique. Amsterdam, Países Bajos: Marc-Michel Rey.

Ruth, S., Welp, Y., \& Whitehead, L. (2017). Let the people rule? Direct democracy in the twenty-first century. Colchester, Reino Unido: ECPR Press.

Schumpeter, J. (1976). Capitalism, socialism, and democracy. Londres, Reino Unido: Allen \& Unwin.

Urbinati, N. (2006). Representative democracy: Principles and genealogy. Chicago, MI: Univeristy of Chicago Press.
Urbinati, N. (2015). El fenómeno populista. Desarrollo Económico, 55(215), 3-20. Recuperado de http://www.jstor.org/stable/43748470

Urbinati, N., \& Warren, M. (2008). The concept of representation in contemporary democratic theory. Annual Review of Political Science, 11(1), 387-412. doi: 10.1146/annurev.polisci.11.053006.190533 Weyland, K. (2001), Clarifying a contested concept: Populism in the study of Latin American politics. Comparative Politics, 34(1), 1-22. doi: $10.2307 / 422412$
Manuscrito recibido: 13-07-2020

Manuscrito aceptado: 15-09-2020 